\title{
What is the impact of the European Consensus on the diagnosis and prevalence of sarcopenia among institutionalized elderly persons?
}

Leônidas de Oliveira Neto ${ }^{1}$

Pedro Moraes Dutra Agrícola ${ }^{2}$

Fabienne Louise Juvêncio Paes de Andrade ${ }^{3}$

Larissa Praça de Oliveira ${ }^{4}$

Kenio Costa Lima ${ }^{3}$

\section{Abstract}

Objective: To verify the impact of the European Consensus on the diagnosis and prevalence of sarcopenia among institutionalized elderly persons in Natal, Rio Grande do Norte, Brazil. Method: 219 elderly persons ( $\geq 60$ years) of both genders were recruited for the study. Two criteria were initially used to calculate the prevalence of sarcopenia: criterion A, based on the European Consensus, considering only elderly persons with good physical and cognitive conditions and criterion B, considering all elderly individuals, regardless of their physical and/or cognitive condition. The association between sarcopenia and gender, age and body mass index (BMI) in the two groups was investigated using the chisquare test and the Student's t-test, with a significance level of 5\%. Result: the diagnosis of sarcopenia according to Criterion A revealed a prevalence of 32\% (95\% CI: 22.54-43.21), whereas Criterion B identified a prevalence of 63.2\% (95\% CI: 56; 45-69,13). Despite the difference in the prevalence of sarcopenia using the two criteria employed $(p<0.001)$, no differences were observed in terms of the association with gender $(p=0.149, p=0.212)$, BMI $(p<0.001, p<0.001)$, and age $(p=0.904, p=353)$. Conclusion: including only elderly people with good physical and cognitive abilities to calculate sarcopenia, based on the European Consensus, underestimates the prevalence of this condition among institutionalized elderly. As elderly persons with physical or cognitive limitations are extremely typical in the population of care facilities and increased diagnostic calculation for sarcopenia did not interfere with the distribution of associated factors, it is recommended that these individuals are considered in the basis of calculation for future studies of the diagnosis and prevalence of sarcopenia.

\footnotetext{
Universidade Federal do Rio Grande do Norte, Departamento de Artes. Rio Grande do Norte, RN, Brasil.

2 Faculdade Maurício de Nassau, Departamento de Educação Física. Rio Grande do Norte, RN, Brasil.

3 Universidade Federal do Rio Grande do Norte, Departamento de Saúde Coletiva. Rio Grande do Norte, RN, Brasil.

4 Universidade Potiguar Laureate International Universities, Departamento de Nutrição. Rio Grande do Norte, RN, Brasil.
}

Keywords: Homes for the Aged. Sarcopenia. Epidemiology. 


\section{INTRODUCTION}

The researcher Irwin Rosenberg (1989) ${ }^{1}$ was a pioneer in identifying the relationship between the reduction in muscle mass and advancing age, using the term "sarcopenia" (from the Greek "sarx" or meat + "penia" or loss) to describe this phenomenon. The association between the reduction of muscle mass and generalized weakness and the functional decline of the elderly has increased research interest in sarcopenia, culminating in a range of studies on the theme $e^{2}$. Despite the simplistic definition that describes sarcopenia as the loss of muscle mass, the adoption of this term in clinical practice has generated several biases for the measurement of the disease, as muscle mass does not represent all the physical alterations and functional complications observed in elderly persons with sarcopenia ${ }^{3,4}$.

The loss of independence and physical capacity associated with sarcopenia has also been related to an increase in the number of falls, frailty, disability and death in this population ${ }^{5-7}$. As a result, the definition of sarcopenia has taken as its main outcome the generalized decline of skeletal muscle mass and strength that comes with advancing age ${ }^{8}$, and the subsequent reduction in quality of life, increased physical disability and the risk of death ${ }^{6,9}$. Sarcopenia is therefore currently classified as a disease under code M62.84, based on the harm caused to the health of the elderly person ${ }^{10}$.

In an attempt to standardize diagnostic criteria for sarcopenia, the European Working Group on Sarcopenia in Older People, Cruz-Jentoft et. al. ${ }^{5}$, recommended the use of indicators of low muscle mass and low muscle function (strength or performance). The gait speed test was used to measure muscle and functional performance, body composition (anthropometric measures) to evaluate body mass index, and hand-grip strength (HGS) to measure the strength of the elderly person.

Despite being widely reproduced in scientific literature as a simple, objective and valid standard for the diagnosis of sarcopenia, the application of the European Consensus (2010) is limited for the study of elderly persons who do not have the physical capacity to perform the gait speed test. In this manner, it excludes wheelchair users and bedridden elderly persons, as well as those that do not have the cognitive capacity required to perform the test, which represents a large section of institutionalized elderly persons ${ }^{11}$.

Considering the methodological limitations for the diagnosis of sarcopenia in the context of the reality of the institutionalized elderly, a model that allows the evaluation of elderly persons with poor conditions of physical and cognitive health must be considered. Therefore, the aim of the present study was to analyze the impact of the European Consensus (2010) on the diagnosis and prevalence of sarcopenia, considering not only ambulatory elderly persons, but also those with physical and cognitive limitations.

\section{METHOD}

The present cross-sectional study was carried out between November 2013 and February 2014 in all $(\mathrm{n}=9)$ private or non-profit Long Term Care Facilities (LTCFs) in the city of Natal, Rio Grande do Norte, Brazil. In total, 219 elderly persons ( $\geq 60$ years) of both genders resident in the institutions were evaluated.

The criteria for inclusion in the study were that all the elderly persons were resident in the LTCFs evaluated and were aged 60 or over (confirmed by an official document). Additionally, the participants were asked to avoid strenuous physical activities, as well as the consumption of alcohol and caffeinated drinks, in the 24 hours prior to the tests.

Excluded from the initial sample were elderly persons who were fed via an enteral tube, those with physiological disorders that impeded the performance of the tests, and those that did not participate in all the stages of the study or that did not take part in all the proposed evaluations. As such, of the initial sample of 314 elderly persons that met the inclusion criteria, 95 were excluded from participation in the study, giving a final sample of 219 subjects.

With the help of a member of staff from each institution, the Mini Mental State Exam (MMSE) ${ }^{12}$ was applied, and the weights and heights of the 
elderly individuals, either actual or estimated by knee height, were measured to calculate Body Mass Index (BMI). To evaluate sarcopenia, we adopted the criteria established by the European Consensus on the Definition and Diagnosis of Sarcopenia (2010), with the aim of stratifying the prevalence of sarcopenia among institutionalized elderly persons. The criteria used were based on the determination of reduced levels of muscle mass (calf perimeter), associated with a reduction in strength (hand-grip strength) and functionality (gait speed), for the diagnosis of sarcopenia among elderly persons $(\mathrm{n}=75)$ with sufficient physical and cognitive conditions (MMSE $>12$ ) for the carrying out of the tests (Criteria A).

Elderly persons with a gait speed greater than $8 \mathrm{~m} / \mathrm{s}$, analyzed by timing the individuals walking a distance of two meters, performed the handgrip strength test (HGST), which involves the application of maximum grip using a Jamar ${ }^{\circledR}$ dynamometer. It was performed with the elderly persons comfortably seated, positioned with the shoulder lightly adducted, the elbow flexed to $90^{\circ}$, the forearm in a neutral position and the wrist extended between $0^{\circ}$ and $30^{\circ}$. Individuals with HGST scores below $30 \mathrm{~kg}$ for men and $20 \mathrm{~kg}$ for women and those with reduced gait speed $(\leq 8 \mathrm{~m} / \mathrm{s})$ underwent calf perimeter measurement. Those with perimeter values below $31 \mathrm{~cm}$ were considered sarcopenic. Values higher than those established for HGST and/or calf perimeter meant the elderly individuals were classified as nonsarcopenic. For bedridden individuals, wheelchair users or those who did not have sufficient physical or cognitive capabilities (MMSE $\leq 12$ ) to perform the gait speed test $(n=144)$, only muscle mass was evaluated (calf perimeter). This strategy was adopted as for this group of elderly persons, the result of gait speed would be $\leq 0.8 \mathrm{~m} / \mathrm{s}$ for physical and/or cognitive comprehension disability and the realization of the test (Criterion B). Additionally, we were able to adopt a criterion that included a larger portion of elderly persons resident in the LTCF.

Initially, the descriptive data were analyzed by mean and standard deviation of BMI, age and prevalence of sarcopenia for comparison of the elderly persons diagnosed according to Criterion $\mathrm{A}$ and Criterion B. For comparison of the mean continuous variables among the groups the Student's t-test was used. The chi-squared test was used for analysis of the qualitative variables, with a data distribution value of $p<0.05$ considered statistically significant.

The project was approved by the Ethics Research Committee of the Universidade Federal do Rio Grande do Norte (Federal University of Rio Grande do Norte) (CEP/UFRN) under approval $\mathrm{N}^{\circ} 308 / 2012$ and was carried out in accordance with the principles of medical research involving humans of the World Medical Association Declaration of Helsinki. Following explanation of the methodological procedures and objectives of the study, all the participants signed a Free and Informed Consent Form prior to the collection of data.

\section{RESULTS}

As can be seen in Figure 1, of the 75 elderly persons who formed part of criterion A, only 18 were able to participate in the HGST, of whom 12 exhibited low strength and underwent calf measurement together with the 57 elderly persons who exhibited low gait speed. In total, 24 elderly persons were considered sarcopenic using criterion $\mathrm{A}$. When criterion $\mathrm{B}$ was applied a further 114 subjects with reduced calf perimeters were added to this total, giving an overall value of 138 sarcopenic elderly persons. 
Criterion A - Exclusive for ambulatory elderly persons with good cognitive conditions.

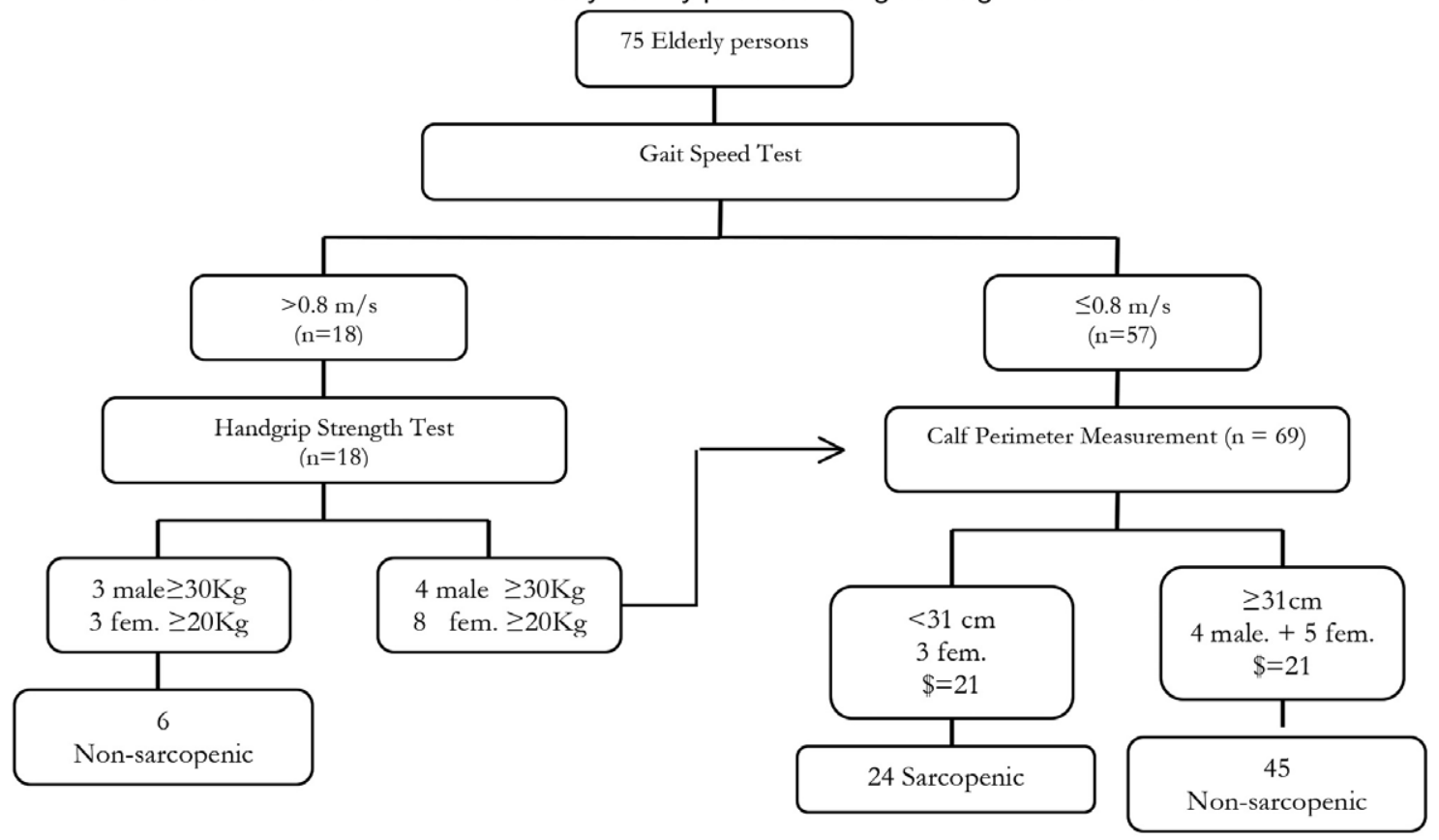

Fem=female.

Criterion B - Includes other non-ambulatory elderly persons and/or those with poor cognitive condition.

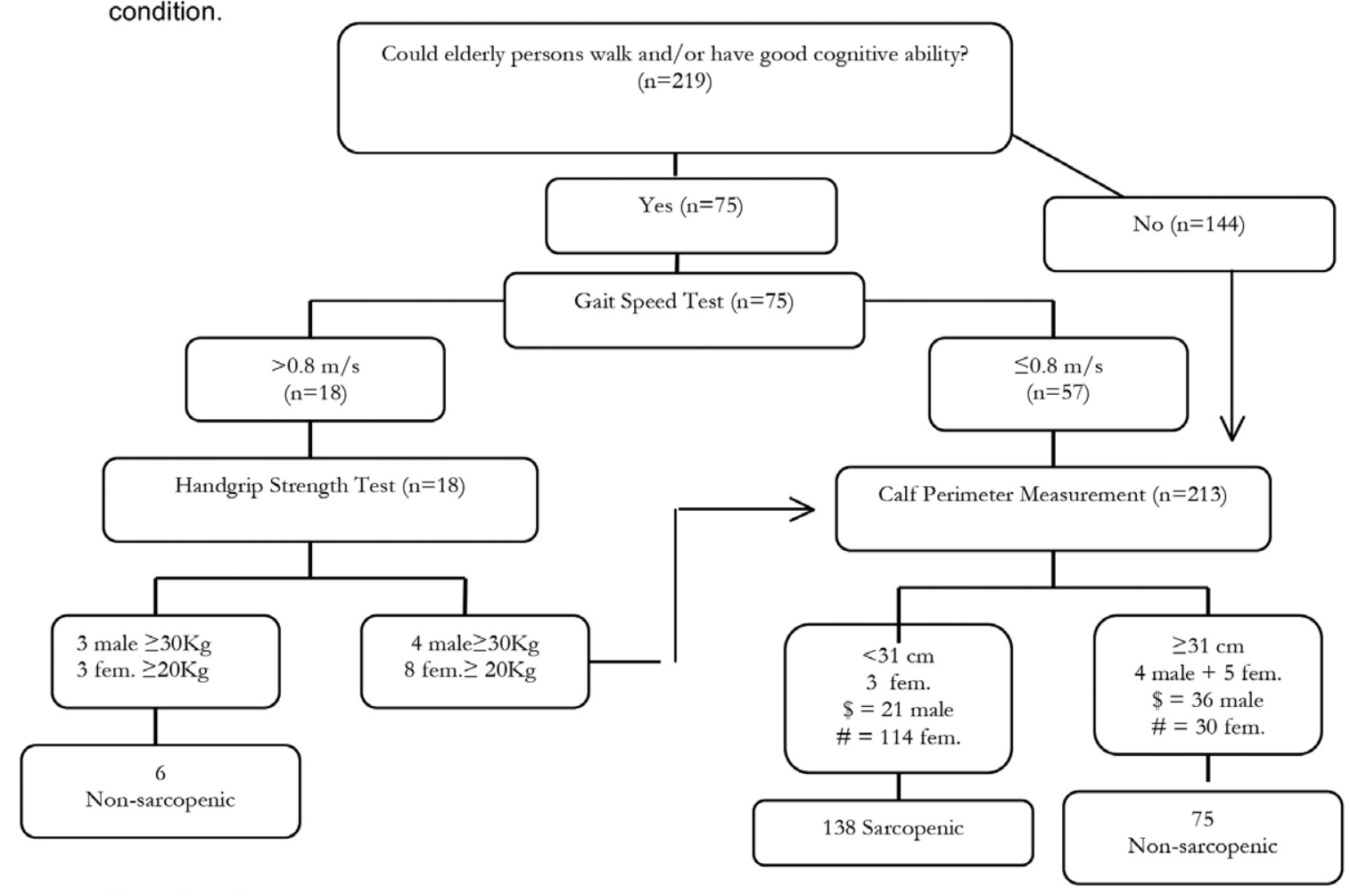

Fem=female.

Figure 1. Flowchart adapted from European Consensus (2010) for the definition and diagnosis of Sarcopenia among institutionalized elderly persons in the city of Natal, using the criteria of functionality (gait speed), strength (handgrip strength) and muscle mass (calf perimeter). Natal, Rio Grande do Norte, 2014. 
When the elderly persons in the sample with sufficient physical and cognitive capabilities to perform the gait speed test (Criterion A) were compared with the other elderly persons who were evaluated for the diagnosis of sarcopenia (Criterion B), Criterion A identified a prevalence of sarcopenia of 32\% (CI95\%: 22.54-43.21), while Criterion B revealed a prevalence of $63.2 \%$ (CI95\%: 56.45-69.13), showing that inserting elderly persons with poor physical/cognitive conditions in the diagnosis of sarcopenia practically doubles the prevalence of the disease. In addition, the Criterion B elderly had a higher mean BMI and a lower mean age than the Criterion A elderly, while no difference was observed in the distribution of gender among the criteria used, as described in Table 1.

Although the elderly persons with low physical and cognitive capacity directly influenced overall prevalence among the institutionalized elderly, as observed in Table 1, the associations with factors such as gender, BMI and age presented the same behavior, irrespective of the parameters of diagnostic analysis of sarcopenia performed in Criterion A and Criterion B (table 2). While BMI was significantly statistically different, with a higher percentage of underweight sarcopenic elderly, gender and age did not differ.

Table 1. Distribution of gender, prevalence of sarcopenia, age and BMI of institutionalized elderly persons from the city of Natal, Rio Grande do Norte (2014) and differences between diagnostic criteria A and B.

\begin{tabular}{llll}
\hline Variables & $\begin{array}{l}\text { Criterion A }(\mathrm{n}=75) \\
\mathrm{n}(\%)\end{array}$ & $\begin{array}{l}\text { Criterion B }(\mathrm{n}=219) \\
\mathrm{n}(\%)\end{array}$ & $P$ value \\
\hline Male & $17(22.7 \%)$ & $49(22.4 \%)$ & 0.334 \\
Female & $58(77.3 \%)$ & $170(77.6 \%)$ & \\
\hline Variables & Criterion A $(\mathrm{n}=75)$ & $\begin{array}{l}\text { Criterion B }(\mathrm{n}=219) \\
\text { Mean }( \pm \mathrm{sd})\end{array}$ & $\begin{array}{c}\text { Mean }( \pm \mathrm{sd}) \\
\text { value }\end{array}$ \\
\hline Age $($ years $)$ & $80.24( \pm 8.74)$ & $84.12( \pm 8.84)$ & $<0.001$ \\
\hline BMI $\left(\mathrm{kg} / \mathrm{m}^{2}\right)$ & $25.89( \pm 5.58)$ & $20.45( \pm 4.64)$ & $<0.001$ \\
\hline
\end{tabular}

${ }^{*}$ Chi-squared test

Table 2. Factors associated with sarcopenia among institutionalized elderly persons in the city of Natal in relation to Criterion A and Criterion B. Natal, Rio Grande do Norte, 2014.

\begin{tabular}{|c|c|c|c|c|c|c|}
\hline \multirow{2}{*}{ Variables } & \multicolumn{2}{|l|}{$\begin{array}{l}\text { Criterion A } \\
\mathrm{n}(\%)\end{array}$} & \multirow[t]{2}{*}{$p$ value } & \multicolumn{2}{|l|}{$\begin{array}{l}\text { Criterion B } \\
\mathrm{n}(\%)\end{array}$} & \multirow[t]{2}{*}{$p$ value } \\
\hline & Sarcopenia & $\begin{array}{l}\text { Non- } \\
\text { Sarcopenia }\end{array}$ & & Sarcopenia & $\begin{array}{l}\text { Non- } \\
\text { Sarcopenia }\end{array}$ & \\
\hline Male & $3(17.6 \%)$ & $14(82.4 \%)$ & 0.149 & $28(57.1 \%)$ & $21(42.9 \%)$ & 0.212 \\
\hline Female & $21(36.2 \%)$ & $37(63.8 \%)$ & & $110(64.7 \%)$ & $60(35.3 \%)$ & \\
\hline $\begin{array}{l}\mathrm{BMI}\left(\mathrm{kg} / \mathrm{m}^{2}\right) \\
\text { Underweight }\end{array}$ & $15(88.2 \%)$ & $2(11.8 \%)$ & $<0.001$ & $105(92.9 \%)$ & $8(7.1 \%)$ & $<0.001$ \\
\hline $\begin{array}{l}\text { BMI }\left(\mathrm{kg} / \mathrm{m}^{2}\right) \\
\text { Normal weight }\end{array}$ & $6(23.1 \%)$ & $20(76.9 \%)$ & & $28(48.3 \%)$ & $30(51.7 \%)$ & \\
\hline $\begin{array}{l}\text { BMI }\left(\mathrm{kg} / \mathrm{m}^{2}\right) \\
\text { Overweight }\end{array}$ & $3 \quad(9.4 \%)$ & $29(90.6 \%)$ & & $5(10.4 \%)$ & $43(89.6 \%)$ & \\
\hline $\begin{array}{l}\text { Age } \\
\geq 80 \text { years }\end{array}$ & $14(32.6 \%)$ & $29(67.4 \%)$ & 0.904 & $90(64.3 \%)$ & $50(35.7 \%)$ & 0.353 \\
\hline $\begin{array}{l}\text { Age } \\
<80 \text { years }\end{array}$ & $10(31.2 \%)$ & $22(68.8 \%)$ & & $48(60.8 \%)$ & $31(39.2 \%)$ & \\
\hline
\end{tabular}

*Chi-squared test; Criterion A: European Consensus (2010); Criterion B: Adapted European Consensus; BMI: Body Mass Index; SARC: Sarcopenia 


\section{DISCUSSION}

The present study revealed that Criterion B elderly persons had a higher mean age and a lower mean BMI than Criterion A elderly. These results were expected, as it has been observed that advancing age is accompanied by a higher incidence of multimorbidities and functional disability, leading to bedridden and wheelchair bound elderly persons ${ }^{13}$. Additionally, such elderly persons suffer a progressive loss of body mass with age, especially in comparison with ambulatory elderly persons ${ }^{6,14}$. It is therefore impossible for elderly persons in such a context to undergo the gait speed test, the criterion used by the European Consensus to diagnose sarcopenia. However, when non-ambulatory elderly persons are included, the prevalence of sarcopenia is $31.2 \%$ higher than when only ambulatory elderly persons are included, corroborating the arguments above and leading to a more accurate prevalence of sarcopenia in LTCFs.

When comparing the two calculations for the diagnosis of sarcopenia used in the present study, it was found that the prevalence among elderly persons who could not walk or who had a poor cognitive condition directly interfered with the overall prevalence among the population of elderly residents of LTCFs. While the calculation used in Criterion A identified $32 \%$ of the elderly persons as sarcopenic, the calculation used in Criterion B practically doubled $(63.2 \%)$ the prevalence of sarcopenic elderly, showing that an approach aimed at the care of sarcopenic elderly persons should be a priority, as the condition affects the majority of LTCF residents.

The bedridden and wheelchair-bound elderly exhibit greater risk factors for a variety of diseases ${ }^{15}$ and naturally present higher frailty indicator scores with the loss of strength and functionality ${ }^{16}$, resulting in a higher prevalence of sarcopenia. This corroborates the findings of the present study, which identified a higher prevalence of sarcopenia when the wheelchair-bound and bedridden elderly of Criterion B were included. This group would also be considered sarcopenic according to the criteria of SARC- $\mathrm{F}^{17}$, which is used for the clinical and diagnostic analysis of sarcopenia. Among the established criteria, difficulties in carrying weight, need for assistance when walking between rooms, difficulty in transferring from the chair to bed, limitations when climbing stairs and the incidence of falls of the elderly are all evaluated. More than two positive answers to these questions are sufficient for the diagnosis of sarcopenia. It can therefore be seen that tasks which are difficult or impossible for the bedridden and wheelchair bound elderly to perform are representative for the categorization of sarcopenia.

Despite the disparity between criteria A and B for the prevalence of sarcopenia, factors associated with BMI, gender and age were distributed in the same manner. While the BMI presented was significantly statistically different among sarcopenic and non-sarcopenic elderly, gender and age revealed no difference. It can therefore be seen that the inclusion of elderly persons with poor physical and cognitive conditions, as well as offering a diagnosis of sarcopenia that best represents the institutionalized elderly population, reveals the same distribution of associated factors as elderly persons with good physical and cognitive conditions, and such criteria are therefore representative from the point of view of both diagnosis and associated factors. In terms of BMI, it was found that most of the elderly were underweight, regardless of the criterion, demonstrating that the loss of mass (muscular or adipose) is a factor directly related to sarcopenia ${ }^{2}$.

In the present study, only calf perimeter was used to measure sarcopenia in the non-ambulatory elderly, as these individuals were unable to achieve a gait speed of $>0.8 \mathrm{~m} / \mathrm{s}$, based on the European Consensus criteria for the diagnosis of Sarcopenia (2010). For the conceptual development of the use of this criterion, the calf perimeter for those who are bedridden/wheelchair-bound can be considered a good predictor of sarcopenia, as this group of elderly people is already weakened, with no muscle strength and/or skeletal muscle, which is why they are unable to walk ${ }^{18,19}$. Although the European Consensus (2010) establishes calf perimeter values below $31 \mathrm{~cm}$ for the diagnosis of sarcopenia, less conservative studies have reported that values below $34 \mathrm{~cm}$ for men and $33 \mathrm{~cm}$ for women indicate low muscle mass and are considered suitable values to predict sarcopenia, with a sensitivity of $88 \%$ and $76 \%$ and a specificity of $91 \%$ and $73 \%$ for men and women respectively ${ }^{18}$.

In spite of this relationship between muscle weakness and sarcopenia, one of the limitations 
of the present study was that it considered only anthropometric evaluation for the diagnosis of sarcopenia in bedridden or wheelchair-bound patients or those with low cognitive ability. The analysis of muscular strength and functionality in the elderly should be considered when fully considering the criteria for the definition of sarcopenia, which in addition to loss of mass is also characterized by the generalized loss of strength and functional capacity that occurs with advancing age ${ }^{8}$. Future studies could analyze whether the use of hand-grip strength in Criterion B would result in a significant change in the prevalence of sarcopenia. In the analyzed data, HGS showed a moderate $(r=0.310)$ and significant $(p=0.007)$ correlation with gait speed, meaning it is possible to relate strength and functionality among institutionalized elderly persons with reduced physical and cognitive capacity.

Careful analysis of the method of diagnosing sarcopenia is extremely important not only for the clarification of the conceptual aspects of this condition, which has recently been classified as a disease $^{6}$, but also to reliably define the prevalence of sarcopenia in the target population studied. The diagnostic analysis of sarcopenia does not consider elderly persons with physical and cognitive restrictions and therefore misrepresents the actual prevalence of the condition, as demonstrated in the present study, reiterating the need for dialogue about the diagnostic methods of sarcopenia and to seek strategies that include elderly persons with physical and cognitive restrictions in the basis of its diagnostic calculation. This information becomes imperative when considering the reality of long-term care facilities in Brazil, due to the high prevalence of health-related factors in this population, with high rates of bedridden individuals, wheelchair users and elderly persons with reduced cognitive capacity ${ }^{11}$.

Strategic government action plans have used prevalence to identify the impact of a disease on a population and the damage it causes to health, mainly to guide strategies to combat illness. When this prevalence reaches representative indicators for a population, new strategies must be used so that health care can be provided effectively. Thus, the change in how the prevalence of a health condition is registered directly impacts the public health strategies designed to combat it ${ }^{20}$. The diagnosis of sarcopenia used by the European Consensus (2010) can therefore have a major impact on the analysis of the prevalence of this disease among institutionalized elderly persons, underestimating diagnostic cases and consequently delaying an epidemiological approach to this health condition. Based on the results found, the use of the criteria adopted in the present study to diagnose sarcopenia in the institutionalized population in Brazil is therefore recommended, as these consider the non-ambulatory elderly and cognitively deficient individuals.

Despite being recommended by the European Consensus (2010), the diagnostic criteria of sarcopenia have some limitations for the analysis of physical performance and muscle mass. Calf perimeter, although recommended, is not selective for muscle mass as it evaluates all such mass, and is not considered a gold standard of body composition assessment. There are also some limitations with respect to physical performance analysis, since the Consensus itself uses a cutoff point for gait speed, but does not establish the precise form of assessment. There may therefore be some variations in the acceleration and deceleration of the method used which can change the final value of gait speed. In addition, there is no reference standard for gait speed and calf perimeter between men and women, as there is with strength.

\section{CONCLUSION}

The diagnostic calculation of sarcopenia considering only the criteria of muscle mass for elderly persons with physical and/or cognitive limitations, in addition to covering a larger population of the elderly, represents the real condition of residents in longterm institutions. Despite the high prevalence, the associated factors of gender, age and BMI are similarly distributed between the two criteria suggested for the diagnosis of sarcopenia. We therefore recommend that this adaptation of the European Consensus criteria for the diagnostic calculation of sarcopenia among non-ambulatory individuals and those with cognitive deficits is used in future studies that seek to evaluate the prevalence of sarcopenia among institutionalized elderly persons. 


\section{REFERENCES}

1. Rosenberg I. Summary comments: epidemiological and methodological problems in determining nutricional status of older persons. Am J Clin Nutr. 1989;50(5):1231-3.

2. Fried LP, Tangen CM, Walston J, Newman AB, Hirsch C, Gottdiener J, et al. Frailty in older adults: Evidence for a phenotype. J Gerontol Ser A Biol Sci Med Sci [Internet]. 2001 [acesso em 30 mar. 2017];56(3):146-64. Disponível em: https://rds185. epi-ucsf.org/ticr/syllabus/courses/83/2012/02/15/ Lecture/readings/fried frailty 2001.pdf

3. Goodpaster BH, Park SW, Harris TB, Kritchevsky SB, Nevitt M, Schwartz A V, et al. The loss of skeletal muscle strength, mass, and quality in older adults: the health, aging and body composition study. J Gerontol Ser A Biol Sci Med Sci [Internet]. 2006 [acesso em 30 mar. 2017];61(10):1059-64. Disponível em: http://www.ncbi.nlm.nih.gov/pubmed/17077199 nhttp://biomedgerontology.oxfordjournals.org/ content/61/10/1059.short

4. Janssen I, Baumgartner RN, Ross R, Rosenberg IH, Roubenoff R. Skeletal muscle cutpoints associated with elevated physical disability risk in older men and women. Am J Epidemiol. 2004;159(4):413-21.

5. Cruz-Jentoft AJ, Baeyens JP, Bauer JM, Boirie Y, Cederholm T, Landi F, et al. Sarcopenia: European consensus on definition and diagnosis. Age Ageing. 2010;39(4):412-23.

6. Shaw SC, Dennison EM, Cooper C. Epidemiology of Sarcopenia: Determinants Throughout the Lifecourse. Calcif Tissue Int [Internet]. 2017 [acesso em 20 abr. 2017];101(3):229-47.Disponível em: http:// link.springer.com/10.1007/s00223-017-0277-0

7. Carmeli E. Frailty and primary sarcopenia: a review. In: Pokorski M, editor. Clinical research and practice. Cham: Springer; 2017. p. 53-68. (Advences Experimental Medicine and Biology); (Neuroscience and Respiration, vol. 1020).

8. Morley JE, Baumgartner RN, Roubenoff R, Mayer J, Nair KS. Sarcopenia. J Lab Clin Med. 2001;137(5):231-43.

9. Henwood T, Hassan B, Swinton P, Senior H, Keogh J. Consequences of sarcopenia among nursing home residents at long-term follow-up. Geriatr Nurs [Internet]. 2017 [acesso em 20 abr. 2017];38(5):40611. Disponível em: http://linkinghub.elsevier.com/ retrieve/pii/S019745721730040X

Received: April 27, 2017

Reviewed: July 18, 2017

Accepted: October 10, 2017
10. Cao L, Morley JE. Sarcopenia is recognized as an independent condition by an International Classification of Disease, Tenth Revision, Clinical Modification (ICD10-CM) Code. J Am Med Dir Assoc [Internet]. 2016 [acesso em 20 abr. 2017];17(8):675-7. Disponível em: http://dx.doi.org/10.1016/j.jamda.2016.06.001

11. Lima-Costa MF, Barreto SM. Tipos de estudos epidemiológicos: conceitos básicos e aplicações na área do envelhecimento. Epidemiol Serv Saúde [Internet]. 2003 [acesso em 21 abr. 2017];12(4):189201. Disponível em: http://scielo.iec.pa.gov. br/scielo.php?script=sci_arttext\&pid=S167949742003000400003\&lng=pt\&nrm=iso\&tlng=pt

12. Brucki SMD, Nitrin R, Caramelli P, Bertolucci PHF, Okamoto IH. Sugestões para o uso do mini-exame do estado mental no Brasil. Arq Neuropsiquiatr. 2003;61(3 B):777-81.

13. Senior HE, Henwood TR, Beller EM, Mitchell GK, Keogh JWL. Prevalence and risk factors of sarcopenia among adults living in nursing homes. Maturitas [Internet]. 2015 [acesso em 15 maio 2017];82(4):41823. Disponível em: http://dx.doi.org/10.1016/j. maturitas.2015.08.006

14. Henwood TR, Keogh JW, Reid N, Jordan W, Senior HE. Assessing sarcopenic prevalence and risk factors in residential aged care: methodology and feasibility. J Cachexia Sarcopenia Muscle. 2014;5(3):229-36.

15. Rosset I, Roriz-Cruz M, Santos JLF, Haas VJ, Fabrício-Wehbe SCC, Rodrigues RAP. Diferenciais socioeconômicos e de saúde entre duas comunidades de idosos longevos. Rev Saúde Pública. 2011;45(2):391-400.

16. Lourenço MT. Capacidade funcional do idoso longevo admitido em unidades de internação hospitalar na cidade de curitiba-PR. Curitiba: Universidade Federal Do Paraná; 2011.

17. Woo J, Leung J, Morley JE.Validating the SARC-F: a suitable community screening tool for sarcopenia? Am Med Dir Assoc. 2014;15:630-4.

18. Kawakami R, Murakami H, Sanada K, Tanaka N, Sawada SS, Tabata I, et al. Calf circumference as a surrogate marker of muscle mass for diagnosing sarcopenia in Japanese men and women. Geriatr Gerontol Int. 2015;15(8):969-76.

19. Tsai H, Chang F. Associations between body mass index , mid- arm circumference, calf circumference, and functional ability over time in an elderly Taiwanese population. PLos ONE. 2017;12(4):1-11.

20. Brasil. Ministério da Saúde, Secretaria de Atenção à Saúde, Departamento de Atenção Básica. Diretrizes para o cuidade das pessoas com doenças crônicas nas redes de atenção à saúde e nas linhas de cuidado prioritárias. Brasília, DF: MS; 2013. 